\title{
TRATAMENTO DE ÁGUA RESIDUÁRIA DE PISCICULTURA UTILIZANDO A TECNOLOGIA DE ELETROCOAGULAÇÃO
}

\author{
Kiane C. L. Visconcin*, Ariovaldo J. da Silva.
}

\section{Resumo}

Sabe-se da grande importância da piscicultura para inúmeros países do mundo, por isso há a necessidade de solucionar os principais desafios com o seu manejo, tais como, a contaminação e poluição das águas dos tanques, causada principalmente pela carga organica e por fosfatos. Um método alternativo de tratamento de efluentes é a tecnologia de eletrocoagulação. Sendo assim, o objetivo do presente trabalho foi avaliar se a tecnologia de eletrocoagulação é eficiente no tratamento de água residuária de piscicultura. A tecnologia de eletrocoagulação se mostrou eficiente na remoção de fósforo total da residuária de piscicultura.

Palavras-chave:

Eletrólise, Tratamento eletroquímico, Limpeza da água.

\section{Introdução}

O manejo de animais aquáticos confinados em tanques gera diversos materiais com elevada carga orgânica, que podem causar a eutrofização da água (MARCEDO; SIPAÚBA-TAVARES, 2010).

Sendo assim, é indispensável a utilização de tecnologias de tratamento para a remoção desses poluentes que degradam e alteram as características do meio aquático, evitando a sua eutrofização.

São utilizadas inúmeras técnicas para o tratamento de efluentes, todavia elas necessitam de grande investimento, mão de obra, tempo, maior espaço e não garantem total eficiência na eliminação dos contaminantes.

Um método alternativo para o tratamento de efluentes é a tecnologia de eletrocoagulação (HEIDMANN; CALMANO, 2007). Essa tecnologia utiliza energia elétrica para flocular as partículas solúveis presentes na água fazendo com que elas flutuam e, por conseguinte possam ser retiradas (GALVÃO; PAGANINI, 2009).

Portanto o objetivo do presente trabalho foi avaliar se tecnologia de eletrocoagulação foi eficiência no tratamento de efluente de tanques de piscicultura

\section{Resultados e Discussão}

Tabela 1 - Resultados das análises da água residuária de piscicultura sem tratamento.

\begin{tabular}{|l|l|l|l|l|l|}
\hline $\mathbf{p H}$ & $\begin{array}{l}\mathbf{N O}_{2} \\
(\mathbf{m g} / \mathbf{L})\end{array}$ & $\begin{array}{l}\text { Turb. } \\
(\mathbf{N T U})\end{array}$ & $\begin{array}{l}\text { Cor } \\
(\mathbf{P t} / \mathbf{C o})\end{array}$ & $\begin{array}{l}\mathbf{P} \text { total } \\
(\mathbf{m g} / \mathbf{L})\end{array}$ & $\begin{array}{l}\mathbf{D Q O} \\
(\mathbf{m g} / \mathbf{L})\end{array}$ \\
\hline 6,70 & 0,45 & 8,75 & 131 & 1,84 & 29,99 \\
\hline \multicolumn{6}{|c|}{ Ao analisar se a água residuária sem }
\end{tabular}

tratamento atende os limites máximos permitidos pela resolução do CONAMA 357, observa-se um desacordo com a norma, portanto necessitando de um tratamento (MANCUSO, 2013). Portando, aplicou-se a eletrocoagulação na água residuária de piscicultura e verificou-se sua eficiência de remoção dos poluentes. $\mathrm{Na}$ Tabela 2 encontram-se os resultados do ensaio após o tratamento eletroquímico.

Tabela 2 - Resultados das análises físico-químicas dos ensaios após o tratamento eletroquímico, usando a tensão de 30 voltz, tempo de 60 minutos e distância de $7 \mathrm{~cm}$.

\begin{tabular}{|l|l|l|l|l|l|}
\hline $\mathbf{p H}$ & $\begin{array}{l}\mathbf{N O}_{2} \\
(\mathbf{m g} / \mathbf{L})\end{array}$ & $\begin{array}{l}\text { Turb. } \\
(\mathbf{N T U})\end{array}$ & $\begin{array}{l}\text { Cor } \\
(\mathbf{P t} / \mathbf{C o})\end{array}$ & $\begin{array}{l}\text { PTotal } \\
(\mathbf{m g} / \mathbf{L})\end{array}$ & $\begin{array}{l}\mathbf{D Q O} \\
(\mathbf{m g} / \mathbf{L})\end{array}$ \\
\hline 7,09 & 0,088 & 2,86 & 3 & 0 & 0 \\
\hline
\end{tabular}

$\mathrm{Na}$ Tabela 3 estão os resultados da porcentagem de remoção dos elementos analisados na amostra após o tratamento eletroquímico.

Tabela 3 - Resultados da porcentagem de remoção dos elementos após o tratamento eletroquímico, usando a tensão de 30 voltz, tempo de 60 minutos e distância de $7 \mathrm{~cm}$.

\begin{tabular}{|l|l|l|l|l|}
\hline $\begin{array}{l}\text { \%Rem } \\
\mathrm{NO}_{2}\end{array}$ & $\begin{array}{l}\text { \%Rem } \\
\text { Turb }\end{array}$ & $\begin{array}{l}\text { \%Rem } \\
\text { Cor }\end{array}$ & $\begin{array}{l}\text { \%Rem } \\
\text { PTotal }\end{array}$ & $\begin{array}{l}\text { \%Rem } \\
\text { DQO }\end{array}$ \\
\hline 80,44 & 67,32 & 97,71 & 100 & 100 \\
\hline
\end{tabular}

Todos os elementos demonstraram grande remoção após a aplicação da eletrocoagulação, principalmente os elementos fósforo e DQO que chegaram a $100 \%$ de remoção.

\section{Conclusões}

A tecnologia de eletrocoagulação é eficiente para o tratamento de água residuária de piscicultura, no entanto, ainda se busca as condições ótimas para o seu funcionamento.

FEAGRI - UNICAMP

\section{Agradecimentos}

PIBITI CNPq

GALVÃO JUNIOR, A.C.; PAGANINI, W.S. Aspectos conceituais da regulação dos serviços de água e esgoto no Brasil. Revista Engenharia Sanitária Ambiental. Fortaleza, Ceará, v.14, n.1, p.79-88, jan./mar., 2009. HEIDMANN, I.; CALMANO, W. Removal of Zn(II), Cu(II), Ni(II), Ag(I) and $\mathrm{Cr}(\mathrm{VI})$ present in aqueous solutions by aluminium electrocoagulation. Journal of Hazardous Materials, v. 84, n.1, p. 83-94, 2007.

KOPARAL A. S.; OUTVEREN, U. B. Removal of nitrate from water by electroreduction and electrocoagulation. Journal of Hazardous Materials, v. 89 n. 1, p. 83-94, 2002. Disponível em: <

https://www.sciencedirect.com/science/article/pii/S0304389401003016>. Acesso em: 22 set. 2018.

MACEDO, C. F.; SIPAÚBA-TAVARES, H. L. Eutrofização e qualidade da água na piscicultura: consequências e recomendações. Boletim de instituto de pesca, São Paulo, v.36, n. 2, p.149-163, 2010.

MANCUSO, P. C. S.; SANTOS, F. dos S. Reuso de água. Barueri, São Paulo: Manole, 2003. 1 Ed. p. 579.

OLIVEIRA JUNIOR, R. P. de; MARTINS, D. E. A.; OLIVEIRA, M. A. S. de. Produção eletroquímica de cloro ativo, uma alternativa viável para processos de desinfecção. In: ENCONTRO DE INICIAÇÃO CIENTÍFICA E PÓS-

GRADUAÇÃO DO ITA, 12., 2006, São José dos Campos, Sp. Anais... . São José dos Campos: Instituto Tecnológico de Aeronáutica, 2006. p. 1 - 7.

Disponível em: 〈http://www.bibl.ita.br/xiiencita/FUND\%2009.pdf〉. Acesso em: 08 out. 2018. 